\title{
Prognostic Value of Technetium-99m-Labeled Single-Photon Emission Computerized Tomography in the Follow-Up of Patients After their First Myocardial Revascularization Surgery
}

\author{
Márcia Maria Sales dos Santos, Eduardo Cwajg, Mauricio da Rocha Pantoja \\ Rio de Janeiro, RJ - Brazil
}

\begin{abstract}
Objective - To assess the prognostic value of Technetium-99m-labeled single-photon emission computerized tomography (SPECT) in the follow-up of patients who had undergone their first myocardial revascularization.
\end{abstract}

Methods - We carried out a retrospective study of 280 revascularized patients undergoing myocardial scintigraphy under stress (exercise or pharmacological stress with dipyridamole) and at rest according to a 2-day protocol. A set of clinical, stress electrocardiographic and scintigraphic variables was assessed. Cardiac events were classified as " $m a-$ jor" (death, infarction, unstable angina) and "any" (major event or coronary angioplasty or new myocardial revascularization surgery).

Results - Thirty-six major events occurred as follows: 3 deaths, 11 infarctions, and 22 unstable anginas. In regard to any event, 22 angioplasties and 7 new surgeries occurred in addition to major events, resulting a total of 65 events. The sensitivity of scintigraphy in prognosticating a major event or any event was, respectively, 55\% and 58\%, showing a negative predictive value of $90 \%$ and $83 \%$, respectively. Diabetes mellitus, inconclusive stress electrocardiography, and a scintigraphic visualization of left ventricular enlargement were significant variables for the occurrence of a major event. On multivariate analysis, abnormal myocardial scintigraphy was a predictor of any event.

Conclusion - Myocardial perfusion tomography with Technetium-99m may be used to identify high-risk patients after their first myocardial revascularization surgery.

Keywords: prognosis, myocardial revascularization, single-photon emission computerized tomography (SPECT)

Universidade Federal do Rio de Janeiro - Cintilab

Mailing address: Márcia Maria Sales dos Santos - Av. Epitácio Pessoa, 4986/501

-22471-001 - Rio de Janeiro, RJ, Brazil - E-mail: msales@cardiol.br

English version by Stela Maris C. e Gandour
The surgical treatment of obstructive atherosclerotic coronary disease has been definitively established as an important therapeutical tool to fight ischemic heart disease.

However, progression of the atherosclerotic disease in native and grafted vessels limits the duration of the benefits obtained with surgery.

Isolated clinical assessment does not provide a clear idea of the anatomical conditions of the vessels (degree of obstruction) and of the risk of future complications due to the influence of several factors.

Most studies on myocardial perfusion scintigraphy and cardiac surgery available in the medical literature were performed with planar Thallium-201 scintigraphy aiming at diagnosing graft disease.

Planar scintigraphy comprises 2-dimensional images of the heart in 3 views: anterior and left anterior oblique at 40 and 70 degrees. With technological advancement, rotational gamma cameras (SPECT) were developed, enabling the acquisition of multiple views of myocardial radionuclide activity and providing an increase in the diagnostic sensitivity of the method.

During approximately 15 years, Thallium-201 was the major radiopharmaceutical tracer used in myocardial perfusion studies. The discovery of new Technetium-99mlabeled myocardial perfusion tracers (sestamibi, teboroxime, tetrofosmin, furifosmin) with better radiolabeled symmetric characteristics favored the generation of excellent-resolution images.

Despite the relevance of the subject and the increase in the amount of myocardial revascularization surgeries performed, little has been published about the use of more advanced scintigraphic techniques, such as myocardial tomography and the new radiopharmaceuticals labeled with Technetium-99m.

This study aimed at assessing the prognostic value of 
Technetium-99m-labeled single-photon emission computerized tomography (SPECT) in the follow-up of patients who had previously undergone their first myocardial revascularization surgery.

\section{Methods}

We carried out a retrospective study designed from a database of a private nuclear cardiology laboratory, from which we selected 1,243 surgically revascularized individuals who underwent myocardial perfusion scintigraphy with the tomographic technique from April 1992 to April 1998.

Technetium-99m-labeled sestamibi or tetrofosmin were the radiopharmaceuticals used. The examinations comprised 2 stages performed in 2 different days: stress (exercise or pharmacological stress with dipyridamole) scintigraphy and scintigraphy at rest.

A single-detector gamma camera with a low-energy high-resolution collimator was used; 32 images with a rotation arch of $180^{\circ}$ were obtained. The images were processed and analyzed in 3 cuts: short axis and vertical and horizontal long axes. The interpretation of the scintigraphies was subjective and semiquantitative (percentage myocardial distribution relative to the pixel of greater intensity) and performed by an independent experienced observer, who ignored the patients' clinical and laboratory data. Doubtful cases required the second opinion of an experienced observer.

Patients with the following characteristics were excluded from the study: third-degree left bundle-branch block; a definitive pacemaker; a history of acute myocardial infarction, percutaneous transluminal coronary angioplasty, or more than 1 myocardial revascularization surgery prior to myocardial scintigraphy; systemic disease that could interfere with the prognosis; patients who had undergone dobutamine stress scintigraphy, and those with a submaximum physical exertion level on exercise testing.

During examination, demographic and clinical data were collected, as were those regarding the risk factors for coronary atherosclerotic disease.

The electrocardiographic findings of the exercise test were classified as negative, positive, or inconclusive for the diagnosis of myocardial ischemia. The test was negative when no change was observed in the ST segment as compared with that on the baseline electrocardiogram. When depression of the ST segment $1 \mathrm{~mm}$ (ascending, descending, or rectified) was observed $80 \mathrm{~ms}$ from the J point, the tracing was considered positive for ischemia. The interpretation of the tracing was considered inconclusive when the baseline electrocardiogram was altered (for example, left ventricular hypertrophy and use of medication).

Myocardial perfusion scintigraphy was considered normal or abnormal (ischemia, fibrosis, or fibrosis associated with ischemia). The examinations with a homogeneous distribution of the radiotracer in the entire left ventricular myocardium on stress and resting images were considered negative for ischemia. Fixed perfusion defects present in both images were interpreted as fibrosis; transient perfusion defects present on stress images and absent on resting images were interpreted as ischemia. When the recovery of these defects was only partial, the simultaneous existence of fibrosis and ischemia was considered.

Left ventricular size was subjectively assessed, based on the cardiothoracic ratio present in the original scintigraphic image of acquisition.

Based on the topography of the myocardial perfusion deficit, a correlation with coronary anatomy was established, and the segments were classified as belonging or not belonging to the region irrigated by the anterior descending artery.

Follow-up was performed through contact with the patient or the assistant physician. The following terminal cardiac events were individually considered: sudden or nonsudden cardiac death; acute myocardial infarction; unstable angina requiring hospitalization; percutaneous transluminal coronary angioplasty; and new myocardial revascularization surgery. These events were categorized into 2 subgroups as follows: "major event" (cardiac death, acute myocardial infarction, and unstable angina) and "any event" (a major event or 1 myocardial revascularization procedure). For the purpose of analysis, only the first event of each patient was considered.

The time interval between revascularization surgery and end of the follow-up (TCABG_END) and that between revascularization surgery and myocardial scintigraphy (TCABG_MS) were analyzed with the Mann-Whitney test.

Data underwent univariate and multivariate analysis. The variables with a $p$ value $<0.05$ and a trend value of $0.05 \leq p \leq 0.1$ were considered statistically significant. The sensitivity, specificity, and positive and negative predictive values of scintigraphy for cardiac events were calculated. Actuarial curves of survival determined with the KaplanMeier method were compiled.

\section{Results}

Of the 1,243 revascularized patients undergoing myocardial perfusion scintigraphy, 879 patients were excluded. Of the 364 remaining patients, 280 (77\%) were followed up.

Lack of evolution information on $84(23 \%)$ patients of the initial sample did not create any type of bias, because the distribution of the variables analyzed was homogeneous between the 2 groups.

The 280 patients contacted were followed up for a mean period of $51 \pm 21$ ( 10 to 88$)$ months. The mean age was $62 \pm 9$ (36 to 84 ) years. The male sex predominated $(80 \%)$. At the time of scintigraphy, $17(6 \%)$ patients had a history of typical angina and $71(25 \%)$ of atypical angina. Two hundred and fifteen (77\%) patients underwent exercise testing, $41 \%$ of whom were negative for ischemia, $24 \%$ positive, and $35 \%$ inconclusive. 
Analysis of temporal data showed that $74 \%$ of the patients had a TCABG_END above 5 years. No correlation was observed between TCABG_MS or TCABG_END and the type of scintigraphic result or the occurrence of cardiac events.

Thirty-six major events occurred as follows: 3 cardiac deaths, 11 myocardial infarctions, and 22 unstable anginas. Of 65 cardiac events classified as "any event," 29 were new myocardial revascularization procedures as follows: 22 angioplasties and 7 reoperations.

No correlation was observed between the type of stress (physical or pharmacological) used, the result of the exercise electrocardiography (positive, negative, or inconclusive), and the result of the myocardial perfusion scintigraphy (normal or abnormal).

The 3 variables that correlated with an abnormal scintigraphic result are shown in figure 1. Left ventricular enlargement on scintigraphy $(\mathrm{p}<0.0001)$ and unstable angina $(\mathrm{p}=0.01)$ and coronary angioplasty $(\mathrm{p}=0.04)$ were associated with the presence of an abnormal scintigraphic finding.

The scintigraphic finding of ischemia $(\mathrm{p}=0.04)$ predominated among the patients who reported the presence of angina pectoris during follow-up. A correlation between the finding of fibrosis $(p<0.001)$ and that of left ventricular enlargement on myocardial scintigraphy was observed.

The analysis of the occurrence of cardiac events and a specific type of abnormal scintigraphic finding (ischemia, fibrosis, and fibrosis with ischemia) identified no association.

On assessing the occurrence of major events, patients with major events were observed to have a trend towards a greater proportion of left ventricular enlargement as compared with that observed in patients with no major event $(\mathrm{p}=0.08)$.

The remaining important variables related to the occurrence of a major event are shown in table I. The subgroup of diabetic patients showed a trend towards a higher proportion $(\mathrm{p}=0.08)$. An association between the presence of angina pectoris $(\mathrm{p}<0.001)$ and left ventricular failure $(p<0.001)$, reported during follow-up, and the incidence of a major event was also observed.

Among the patients with any cardiac event, no predo-

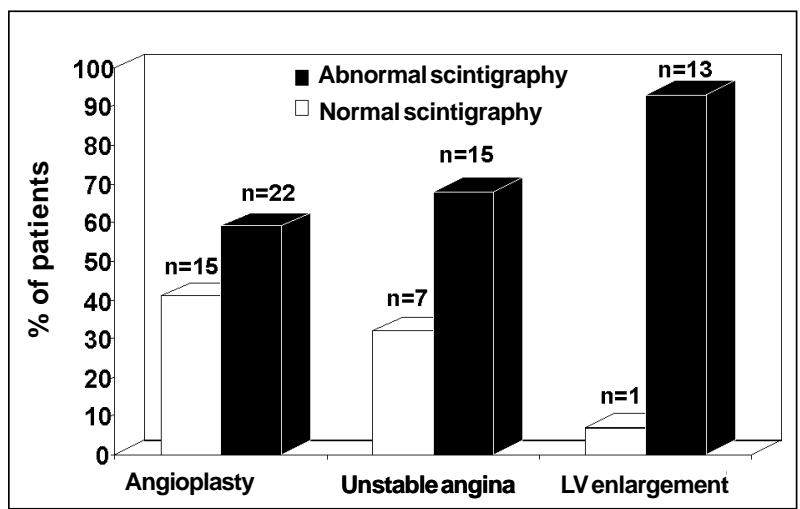

Fig. 1- Comparison of clinical and scintigraphic covariables with the result of myocardial scintigraphy. LV- left ventricle.

\begin{tabular}{|lccc|}
\hline \multicolumn{3}{|c|}{ Table I - Comparison of clinical covariables and major cardiac events } \\
\hline \multirow{2}{*}{ Variables } & \multicolumn{2}{c|}{ Patients } & \\
\cline { 2 - 3 } & $\begin{array}{c}\text { No major } \\
\text { event N(\%) }\end{array}$ & $\begin{array}{l}\text { With major } \\
\text { event N(\%) }\end{array}$ & \\
\hline Male sex & $195(80)$ & $28(78)$ & NS \\
Angina pectoris & $53(22)$ & $18(50)$ & $<0.0001$ \\
LV failure & $8(3)$ & $9(25)$ & $<0.0001$ \\
Arterial hypertension & $72(30)$ & $13(36)$ & NS \\
Diabetes mellitus & $24(10)$ & $7(19)$ & 0.08 \\
Dyslipidemia & $90(37)$ & $13(36)$ & NS \\
Exercise ECG & & & \\
inconclusive & $58(31)$ & $16(62)$ & 0.02 \\
\hline LV- left ventricle; ECG- electrocardiogram. & \\
\hline
\end{tabular}

minance of the demographic variables studied was observed. The presence of angina pectoris $(\mathrm{p}<0.001)$ and left ventricular failure $(p<0.001)$ during follow-up related to the incidence of "any event."

An altered scintigraphic result showed a good correlation with the occurrence of "any event" (tab. II).

On multivariate analysis, the presence of diabetes mellitus and left ventricular enlargement showed a trend towards stressing the probability of the occurrence of major events. For the "any cardiac event" model, the altered scintigraphic result had a significant statistical value (tab. III).

To analyze the prognostic value of myocardial perfusion scintigraphy, sensitivity, specificity, and the negative and positive predictive values were calculated (tab. IV).

The actuarial survival curves free from a "major cardiac event" or "any cardiac event" are shown in figures 2 and 3.

\section{Discussion}

The major applications of nuclear cardiology in the follow-up of revascularized patients comprise the diagnosis of intraoperative myocardial injury and atherosclerotic disease of the native or graft bed, the documentation of reduction of the ischemic area, the analysis of ventricular function in the postoperative period, and the prediction of cardiac events.

During the follow-up of the revascularized patients, those at risk for developing future cardiac events need to be identified. On detecting patients at higher risk for cardiac

\begin{tabular}{|c|c|c|c|}
\hline \multicolumn{4}{|c|}{$\begin{array}{c}\text { Table II - Comparison of the result and impaired area on myocardial } \\
\text { scintigraphy and any cardiac event }\end{array}$} \\
\hline \multirow{2}{*}{$\begin{array}{l}\text { Myocardial } \\
\text { scintigraphy result }\end{array}$} & \multicolumn{2}{|c|}{ Patients } & \multirow[b]{2}{*}{$\mathrm{P}$} \\
\hline & $\begin{array}{c}\text { Without any event } \\
\mathrm{N}(\%)\end{array}$ & $\begin{array}{c}\text { With any event } \\
\mathrm{N}(\%)\end{array}$ & \\
\hline Normal & $129(83)$ & 27 (17) & NS \\
\hline Abnormal & $86(69)$ & $38 \quad(31)$ & 0.009 \\
\hline Non AD irrigated area & $43(50)$ & $19(50)$ & NS \\
\hline $\mathrm{AD}$ irrigated area & $43 \quad(50)$ & $19(50)$ & NS \\
\hline
\end{tabular}




\begin{tabular}{|lccc|}
\hline \multicolumn{4}{|c|}{ Table III - Independent predicting variables of any cardiac event } \\
\hline $\begin{array}{l}\text { Predicting variables } \\
\text { of any event }\end{array}$ & $\mathrm{P}$ value & Odds ratio & $\begin{array}{c}95 \% \text { confidence } \\
\text { interval }\end{array}$ \\
\hline $\begin{array}{l}\text { Abnormal myocardial } \\
\text { scintigraphy }\end{array}$ & 0.008 & 2.11 & $1.20-3.72$ \\
\hline
\end{tabular}

\begin{tabular}{|lcc|}
\hline \multicolumn{2}{|c|}{ Table IV - Prognostic value of myocardial scintigraphy } \\
\hline Myocardial scintigraphy & Major event & Any event \\
\hline Sensitivity (\%) & 56 & 58 \\
Specificity (\%) & 57 & 60 \\
Predictive value (\%) & & \\
positive & 16 & 31 \\
negative & 90 & 83 \\
Accuracy (\%) & 57 & 60 \\
\hline
\end{tabular}

events, the subgroup that benefits most from a more invasive treatment is identified, due to an improvement in quality of life and a reduction in mortality.

Basically, the results were published of 4 studies ${ }^{1-4}$ that analyzed the prognostic power of exercise myocardial scintigraphy in the follow-up of patients undergoing myocardial revascularization surgery.

The first study was performed by Palmas et al ${ }^{1}$, who assessed 294 patients undergoing exercise testing and Thallium-201 SPECT. On multivariate analysis, the scintigraphic variables of statistical significance for the occurrence of events were the reversibility score and increased pulmonary uptake. Another important finding was that scintigraphic information had a greater prognostic value than the association of clinical history and exercise testing.

Nallamothu et al. ${ }^{2}$ carried out the second study in which the prognostic value of Thallium-201 myocardial scintigraphy was assessed. The extension of the perfusion defect, the perfusional changes in multiple areas, and the increase in pulmonary uptake were independent predictors of cardiac events (a $9.3 \%$ risk per year).

In a study by Miller et $\mathrm{l}^{3}$ using exercise tomographic scintigraphy with Thallium-201, the extension of the perfu-

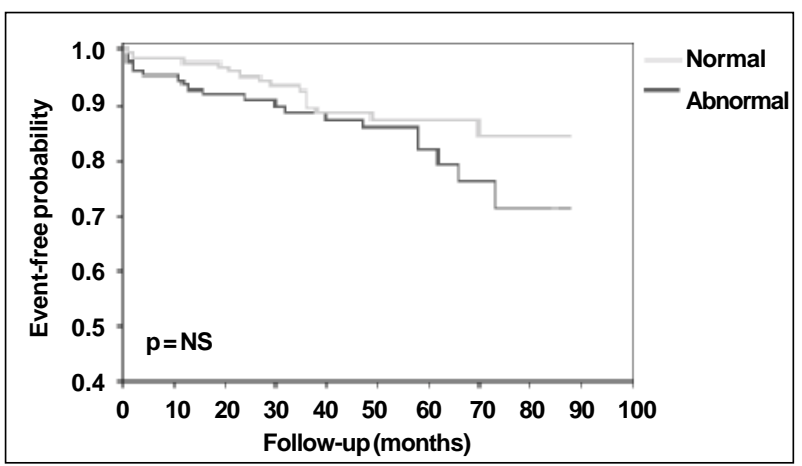

Fig. 2 - Actuarial curve of survival free from major cardiac event with normal and abnormal scintigraphy.

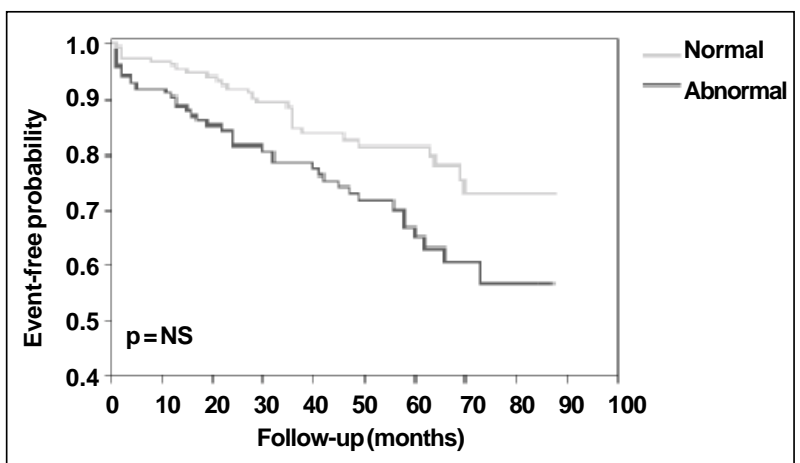

Fig. 3 - Actuarial curve of survival free from any cardiac event with normal and abnormal scintigraphy.

sion defect was the only independent variable able to predict events. The patients with normal myocardial perfusion had an annual event ratio of $1.6 \%$.

In another study carried out at the Cleveland Clinic ${ }^{4}$ with tomography and Thallium-201 in asymptomatic revascularized patients, the group with abnormal scintigraphic findings had a greater incidence of cardiac events (11\%) than that with normal imaging (4\%).

In our study, strict inclusion and exclusion criteria were defined aiming at minimizing the possible clinical situations that could interfere with the interpretation of and determination of the value of myocardial perfusion scintigraphy. This is the case of patients with a previous history of acute myocardial infarction in whom a myocardial perfusion deficit in imaging compatible with the infarcted area may occur. The same occurs in third-degree left bundle-branch block or pacemaker rhythm, in which a decreased uptake pattern, respectively, at the level of the ventricular septum and inferior wall may be visualized even in the absence of obstructive coronary artery disease. However, in most published studies, this preoccupation was not observed.

During follow-up, the total rate of major events (cardiac death, myocardial infarction, or unstable angina) was $12.8 \%$, and the total rate of any cardiac event (major events, angioplasty, or revascularization surgery) was $23.2 \%$. It is worth noting that revascularized patients comprise a subgroup, in which the treatment of coronary artery disease has already been instituted and a lower rate of cardiac events is expected.

Of the clinical and demographic variables evaluated by the univariate analysis, no association with the type of scintigraphic result was observed. This finding is in accordance with those of other published studies.

Univariate analysis identified a trend of the diabetes mellitus risk factor towards being associated with the occurrence of major events $(\mathrm{p}=0.08)$. This probable importance of diabetes mellitus in predicting major events has also been reconfirmed on multivariate analysis $(p=0.07)$. The importance of the diabetes mellitus risk factor in the severity of atherosclerotic disease of the native bed ${ }^{5-8}$ has been well demonstrated. A more diffuse and extensive atherosclerotic impairment of coronary arteries is believed to be the motive. 
On univariate analysis, the cardiac symptoms present during follow-up, such as angina pectoris $(\mathrm{p}=0.001)$ and the clinical manifestations of left ventricular failure $(\mathrm{p}=0.001)$, appeared as important variables in the subgroup of patients with major events.

The determination of the value of precordialgia after myocardial revascularization surgery is extremely complex. The pain may be caused by osteoarticular, neurological, and muscular factors proper to the surgical procedure. However, the presence of typical angina has been reported as a strong indicator of ischemia and of the presence of significant coronary lesions on the hemodynamic study ${ }^{9}$.

On assessing the modality of stress used (physical or pharmacological with dipyridamole), no difference was observed in the scintigraphic result and in event prediction. However, when studying separately the electrocardiographic pattern of the exercise test (normal, ischemic, or inconclusive), the subgroup of patients with major events showed a greater proportion of inconclusive exercise electrocardiogram results $(p=0.02)$. The patients with an inconclusive exercise test may have been those with more significant disease and, consequently, with persistent changes on the resting electrocardiogram.

On univariate analysis, the patients undergoing percutaneous angioplasty had a greater association with abnormal images $(p=0.04)$. Interference of the result of the test with the decision-making process of the assistant physician could not be evaluated.

When the scintigraphic variables were studied on univariate and multivariate analysis, the patients with the scintigraphic pattern of left ventricular enlargement were observed to have a greater proportion of altered myocardial perfusion imaging and major events.

Left ventricular dysfunction is an independent marker of poor prognosis. It is a fact that left ventricular size and the dysfunctional degree of the ischemic cardiac muscle are directly correlated with the dimension and intensity of decreased myocardial uptake on scintigraphy and with the extension and severity of the coronary artery disease on coronary angiography ${ }^{6,7}$.

Postexercise Thallium-201 pulmonary uptake is a signal of ventricular dysfunction and extensive atherosclerotic disease. Transient left ventricular dilation on exercise imaging is caused by ischemic ventricular dysfunction and indicates the presence of severe atherosclerotic disease ${ }^{6,7}$.

The scintigraphic visualization of left ventricular enlargement, similarly to other indirect signs of left ventricular dysfunction like Thallium-201 pulmonary uptake, transient left ventricular ischemic dilation, extension of decreased myocardial uptake greater than $15 \%$ of the left ventricular area, and defects of myocardial uptake in multiple areas, are independent markers of poor prognosis and cardiac mortality ${ }^{10-12}$.

The association of the presence of an abnormal scintigraphic result and the occurrence of any cardiac event had statistical significance $(\mathrm{p}=0.009)$. No specific type of scintigraphic result (ischemia, fibrosis, or fibrosis with ischemia) predominated in predicting cardiac events. These findings did not partially agree with those reported in other studies in which ischemia was an important scintigraphic finding.

The event-free actuarial curves clearly show the influence of the appearance of myocardial scintigraphy in the occurrence of events throughout time. They illustrate that the presence of a normal scintigraphy is a positive indication of event-free survival, which is in accordance with the importance of the negative predictive value of the examination.

In our study, sensitivity, specificity, positive predictive value, and mainly negative predictive value cited in the literature could not be specifically reproduced. Discordance with previous publications may be due to differences in sample selection and limitations inherent in the study design.

The major limitation of this study might have been the lack of application of quantitative methods of analysis and interpretation on scintigraphy. The interpretation of myocardial perfusion images was subjective, identifying impaired left ventricular myocardial areas. However, according to the literature, this type of analysis has a performance similar to that of quantitative analysis ${ }^{5-7}$. We should not also neglect the prognostic clinical importance of assessing the extension and intensity of the myocardial uptake deficit and of the reversibility of the decreased perfusion. This quantitative analysis may have strengthened the prognostic accuracy of myocardial scintigraphy in this study.

The use of ventricular functional assessment software could have increased the prognostic value of myocardial scintigraphy found in this study. Currently, with computer programs, left ventricular endocardial and epicardial borders may be defined on the acquisition of tomographic myocardial perfusion images (Thallium-201 or Tc-99m-labeled agents) synchronized with the cardiac cycle by the electrocardiographic QRS complex (gated SPECT).

The software of the gated SPECT allows the evaluation of systolic thickening, segmentary and global contraction, and the calculation of left ventricular volumes and ejection fraction. This facilitates the differentiation between artifactual and actual defects, with a consequent reduction in the number of false-positive examinations and an increase in the specificity of the method.

Unfortunately, anatomic information about the coronary circulation and the aortocoronary grafts, which would complement the functional evaluation, could not be obtained. However, it is worth noting that the objective of this study was not to evaluate graft patency on scintigraphy, but the prognosis.

Therefore, this study with patients after their first myocardial revascularization surgery undergoing stress myocardial perfusion scintigraphy with Technetium-99m-labeled radiopharmaceuticals shows that the presence of an abnormal myocardial perfusion scintigraphy is an independent variable for predicting cardiac events (death, myocardial infarction, unstable angina, coronary angioplasty, and new myocardial revascularization surgery). 


\section{References}

1. Palmas W, Bingham S, Diamond GA, et al. Incremental prognostic value of exercise Thallium-201 myocardial single-photon emission computed tomography late after coronary artery bypass surgery. J Am Coll Cardiol 1995; 25: 403-9.

2. Nallamothu N, Johnson JH, Bagheri B, et al. Utility of stress single-photon emission computed tomography (SPECT) perfusion imaging in predicting outcome after coronary artery bypass grafting. Am J Cardiol 1997; 80: 1517-21.

3. Miller TD, Christian TF, Hodge DO, et al. Prognostic value of exercise Thallium201 imaging performed within 2 years of coronary artery bypass graft surgery. J Am Coll Cardiol 1998; 31: 848-54.

4. Lauer MS, Lytle B, Pashkow F, et al. Prediction of death and myocardial infarction by screening with exercise Thallium testing after coronary-artery-bypass grafting. Lancet 1998; 351: 615-22.

5. Braunwauld E. Heart disease: A Textbook of Cardiovascular Medicine. $5^{\text {th }}$ ed. Philadelphia: WB Saunders, 1997: 1996p.
6. Zaret BL, Beller GA. Nuclear Cardiology: State of the Art and Future Directions. $2^{\text {nd }}$ ed. Philadelphia: Mosby, 1999: 640p.

7. Iskandrian AS, Verani MS. Nuclear Cardiac Imaging: Principles and Applications. $2^{\text {nd }}$ ed. Philadelphia: F.A. Davis Co., 1996: 451p.

8. Topol E, CallifRM. Textbook of Cardiovascular Medicine. Philadelphia: Lippincott, Willians \& Wilkins, 1997: 2760p.

9. PimentelCX, Paranandi SN, Goodhart DM, et al. Clinicals markers, management, and long-term follow-up of early ischemia after coronary artery bypass grafting. Am J Cardiol 1995; 76: 967-72.

10. Gibson RS, Watson DD. Value of planar Tl-201 imaging in risk stratification of patients recovering from acute myocardial infarction. Circulation 1991; 84(suppl I): I-148-62.

11. Brown KA. Prognostic value of Thallium-201 myocardial perfusion imaging. Circulation 1991; 83: 363-81.

12. Brown K. Prognostic value of Thallium-201 myocardial perfusion imaging in three primary patient populations. Am J Cardiol 1992; 70: 23E-29E. 